\title{
The Dilemma and Countermeasures of China's Manufacturing Industry Development
}

\author{
Qianqiu Luo \\ School of Economics \\ Sichuan University \\ Chengdu, China 610065
}

\begin{abstract}
At present, as China's income gap is widening, consumer demand insufficient, the consumption structure unbalanced, the manufacturing industry is also facing the dual pressures on technology and market. This paper argues that the market pressure China's manufacturing industry is facing is on the one hand from the insufficient consumption caused by income distribution problem, on the other hand, from the sluggish growth of China's exports caused by the implementation of the "re-industrialization" in western countries. Therefore, to solve the problems of China's manufacturing industry, the government must not only start from the supply side, but also focus on the reform of the demand side. On the one hand, we should increase the income of the residents, narrow the gap between the rich and the poor, so as to promote consumption. On the other hand, we should change the mode of foreign trade, improve the qualityl of manufacturing technology.
\end{abstract}

Keywords-manufacturing industry; demand; technology; countermeasures

\section{INTRODUCTION}

For the problems of China's manufacturing industry development, Shimei Li (2004), Yulun Lin (2010), Yibo Xiang (2013) and other scholars have conducted a lot of research. These studies focus on the analysis of China's low level of manufacturing technology in the equipment manufacturing industry, low labor productivity, short of independent intellectual property rights, lags of reform of organization and management system in the manufacturing industry, obtained many enlightening conclusions, and put forward many valuable suggestions. However, the researches on the problems of the manufacturing sector, basically analyze the problems directly show in the manufacturing industry more and residents' consumption capacity, consumption structure for manufacturing market, restrictions on the upgrade of manufacturing technology from the international division of labor less. This paper attempts to analyze the problems of manufacturing industry development in China from two aspects of supply and demand, and puts forward some countermeasures.

\section{CHINA'S MANUFACTURING INDUSTRY UPGRADE DILEMMA}

\section{A. Market Expansion Pressure}

The transformation and upgrading of the manufacturing industry cannot do without the expansion of the market. On the one hand, China's domestic consumption is seriously restricting the expansion of the domestic market of China's manufacturing industry. The long-term experience of developed countries shows that growth of final consumption substantially remains similar to that of GDP. But China's annual growth rate of final consumption is lower than the growth rate of GDP in the long run. Since 1994, in the construction of a socialist market economy, China's longterm consumption rate is too low, and there is a long-term downward trend. China's final consumption rate rose from $57 \%$ in 1994 to $62.85 \%$ in 2000 , and then showed a gradual downward trend from 2000, reaching the lowest point in the year of 2010. In the same period, in some developed countries such as the United States and France, the final consumption rate was always above $76 \%$, the highest reached $83.19 \%$. Therefore, compared with developed countries or developing countries, China's final consumption rate is at a low level.

On the other hand, in recent years, China's export growth is weak, leading to the pressure of expansion of manufacturing overseas markets. The export growth rate of all goods and trade in China has declined from $19.97 \%$ in 1994 to $0.05 \%$ in 2016

\section{B. Technical Upgrading Pressure}

Manufacturing upgrading must be built on a high level of technology. However, at present, China's manufacturing industry is facing greater pressure to upgrade the technology. Equipment manufacturing industry is the core component of the manufacturing sector and the foundation of the national economic especially industrial development, it provides production technology equipment for the national economy and national defense construction. However, China's equipment manufacturing industry is in the low end of the international division of labor, the technical level of it lags behind the developed countries and has a high dependence on foreign countries. Although China's equipment manufacturing industry developed rapidly, but the key technology of external dependence is more than $50 \%$, while 
the developed countries are below 30\%, the United States and Japan is only about $5 \%$.

On the other hand, the rate of capital formation, that is, the proportion of the total capital formation of a certain period of time, to a certain extent, reflects the technical level of manufacturing industry. From 1994 to 2015, China's total capital formation rate was in an overall upward trend, first dropped from $40.95 \%$ in 1994 to its lowest level of $34.43 \%$ in 2000, and then showed a rising trend, reached the highest point of $47.67 \%$ in 2011, was still as high as $45.40 \%$ in 2015 . Overall, China's capital formation rate is much higher than that in developed countries such as the United States, Britain and France and developing countries such as India, Brazil and South Africa. Except India, China's capital formation rate is about 2-3 times of those countries.

\section{REASON ANALYSIS}

\section{A. The Reasons for the Formation of Market Expansion Pressure}

Since the reform and opening up policy, the income growth of urban and rural residents in China is slow comparing to GDP. The income gap between Different social strata, Different regions, urban and rural areas is widened, the Gini coefficient is higher the that in many developed countries, which leads to the weakening of the average consumption tendency of the whole society and is an important reason for the lack of consumption demand and low consumption rate. Since the construction of the socialist market economy in our country, Keynes doctrine, the demand side management, which is the anti-crisis function of the government, has been abused to deal with the economic growth. The long-term aggregate demand side management results in the expansion of the income gap and the incompatibility of supply and demand. In China's urban and rural structure, the problem manifests as the gap of rural and urban residents in not only the absolute number but also the structure respect.

On the one hand, the absolute consumption gap between urban and rural residents in China is very large. From 2013 to 2015 , the per capita consumption expenditure of rural residents was 7485.10 yuan, 8382.60 yuan and 9222.60 yuan, per capita consumption expenditure of urban residents was 18487.5 yuan, 19968.1 yuan and 21392.4 yuan, the consumption expenditure of urban residents is about 2.5 times as much as that of rural residents. On the other hand, the proportion of expenditure in China's residents shows a high proportion of basic material consumption, and a small proportion of the expenses of spiritual and cultural life, labor and health care. From 2013 to 2015, urban residents per capita food consumption expenditure accounted for $34.14 \%$, $29.42 \%, 29.10 \%$ of the total proportion, per capita traffic consumption expenditure accounted for $14.80 \%, 13.18 \%$, $13.51 \%$ of the total proportion; in contrast, per capita consumption expenditure of education and entertainment accounted for $12.41 \%, 10.72 \%, 11.13 \%$, per capita healthcare spending accounted for $6.05 \% 5.20 \%, 5.39 \%$. Similarly, the consumption expenditure of rural residents, per capita food consumption expenditure accounted for $34.10 \%, 33.60 \%, 33 \%$ of the total expenditures, while the per capita consumption expenditure of education and entertainment accounted for $10.10 \%, 10.30 \%, 10.50 \%$, health care expenditure accounted for $8.90 \%, 9 \%, 9.20 \%$.

Since the 2008 financial crisis, China's economy has suffered a severe blow, 2009 net export contribution rate to GDP was $44.8 \%$, pull only 3.9 percentage points of GDP, export-oriented growth model has come to an end, if there is no domestic demand, especially with consumer demand, it will be difficult to maintain. In addition, the United States and Europe now implement the "re-industrialization" strategy, which advocates the return to the real economy and concentrate the domestic industrial investment, to avoid hollowing out the industrial structure. This reindustrialization plan is to promote exports through the revitalization of manufacturing, change the mode of consumption, balance trade. China has been implementing an export-oriented trade policy for a long time, the international economic situation and European industrial policy changes have a very negative impact on China's manufacturing exports, thus forming a larger foreign market expansion pressure.

\section{B. Reasons for the Pressure of Technological Upgrading}

Since 1990s, in the process of building a socialist market economy, China has gradually formed a foreign tradeoriented economic development model. Under the influence of various factors, such as attracting foreign investment and demographic dividend, exports gradually become a powerful tool for stimulating economic growth and improving employment levels. Accordingly, the manufacturing industry is mainly labor - intensive, forming a pattern of economic growth characterized by "international subcontracting" in the coastal areas. There is a big gap between China and developed countries such as the United States and Japan in the field of capital intensive and technology intensive manufacturing. It can be said that the production technology especially key technology that China's manufacturing relies on came largely from abroad. China is lack of well-known brands with independent intellectual property rights, rely heavily on overseas suppliers and importers in information sources and sales channels.

Therefore, from the global system of international division of labor, most of China's traditional industrial cluster is currently most labor-intensive products in production and assembly, with low technological content, low value-added sectors, in the low end of the smile curve in global value chains. In addition, because of the low starting point of production, low entry barriers of the industry, the internal product homogenization phenomenon is serious in many of China's traditional industrial cluster, the production of the products are facing pressure from technical barriers and trade protectionism in the international market.

\section{CONCLUSION AND POLICY RECOMMENDATIONS}

Fundamentally speaking, China's manufacturing industry is facing pressure to expand the market and the pressure of technological upgrading, which mostly because that we emphasize more on foreign demand and ignore the domestic demand in the long-term development. The current economic 
situation shows that it is impossible to continue to adhere to the export-oriented economic growth model. Therefore, to improve the domestic market and expand domestic consumption at the same time, enhance the level of manufacturing technology and the status of the international division of labor, is the effective measure to enable our country manufacturing industry to get rid of the dilemma of market and technology.

Firstly, in terms of demand, fiscal policies should focus on raising the level of individual consumption and increasing domestic effective demand. Through the establishment of a scientific and reasonable income distribution mechanism, the pace of construction of the social security system can be accelerated, menace from the rear of the consumer lift. We should actively support the development of the consumer service industry and the production service industry, and establish a sound consumption support system. The policy toward farmers should turn to vigorously develop the rural economy, expand the overall scale of consumption, adjust the agricultural structure, increase the efficiency of agricultural production and increase the income of farmers. Investment in public finance should be intensified so as to improve the basic conditions of agricultural production and the consumption environment of farmers. Urbanization can stimulate investment demand and expand private investment, which is conducive to the transformation and upgrading of the industrial structure and to promote economic services. To link the domestic demand expanding and the process of urbanization in China closely, to achieve a positive interaction between economic development and domestic demand, is an effective way to expand domestic demand and promote growth.

Secondly, on the supply side, economic policies should focus on the use of new and high technology to transform traditional industries and improve the technological structure of traditional industries. In view of the obsolete equipment, backward technology of China's traditional industries, using high technology to transform traditional industries is to strengthen the radiation and osmosis of new and high technology to traditional industries, so that the regulatory departments should equip and transform production tools, labor objects and technological processes with new and high technology. We should encourage enterprises to adjust the product structure, transform traditional industries with energy saving technology, and shut down the small enterprises of low utilization rate of resources and ecological destruction resolutely, eliminate backward technology, improve product technology content, promote the upgrading of products with advanced equipment and technology. On this basis, the new industrial policy should be beneficial to adapt to the new market demand at home and abroad, increase the investment of technological transformation of traditional industries, widely used new technology and new equipment for the transformation of traditional industries, optimize the product structure, industrial structure and organizational structure through technological innovation, open up new areas and occupy the market. At the same time, government should pay attention to induce the extensive use of high technology and advanced applicable technologies to guide the traditional industries to achieve clean, green, efficient, low consumption, sound production, implement the strategy of sustainable development of low resource consumption and less environmental pollution, thus forming strong international competitive advantage of the traditional industry of our country and promoting China's industrialization and the process of modernization.

\section{REFERENCES}

[1] Shimei Li, "Study on the main problems and Countermeasures of the development of Chinese manufacturing industry", Journal of Central University of Finance and Economics, Beijing,2004, No. 12, pp.55-59.

[2] Yulun Lin,"A Research on China Current Manufacturing and International Comparison", Journal of North China Electric Power University(Social Sciences), Beijing,2010,No.3, pp. 32-37.

[3] Yibo Xiang, Chunfang Zheng,"Countermeasures to improve the international competitiveness of China's equipment manufacturing industry", Economic Review, Changchun , Jilin, 2013,No.4, pp. 7476.

[4] Jinhua Li, Cangshu Li, "Manufacturing Industry in China under the New International Background: the Paradoxes and Its Countermeasures", Shanghai Journal of Economics, Shanghai, 2010,No.4, pp. 3-11.

[5] Dongwei Wen, "The Technological Structure of Chinese Manufacturing Exports and Its International Comparison", World Economy Study, Shanghai, 2012,No.10, pp. 29-34. 